\title{
Analisis Komponen Utama Pada Data Potensi Kecamatan di Kota Palu Sebelum Bencana Gempa Bumi dan Tsunami 28 September 2018
}

\author{
Drajat Indra Purnama*
}

\begin{abstract}
On 28th September 2018, a 7.4 magnitude earthquake hit Palu and was followed by tsunami soon after. The combined effects of the earthquake and tsunami led to the deaths of thousands people, thousands of people had been displaced, and dozens of structures were either damaged or destroyed in Palu. Moreover, the impact of the disaster took effect to the development of Palu. The long term development of Palu suddenly struck and scattered by the earthquake and tsunami. This research is focused on the sub-district potential in Palu before the earthquake and tsunami. The data is taken from the publication of BPS-Statistics Palu "Kota Palu dalam Angka 2018". The variables used in this research cover multiple aspects such as geography, government, social, transportation, communication, and economy. The variables are the large area of sub-district $\left(X_{1}\right)$, village $\left(X_{2}\right)$, population $\left(X_{3}\right)$, elementary school $\left(X_{4}\right)$, junior high school $\left(X_{5}\right)$, senior high school $\left(X_{6}\right)$, health facility $\left(X_{7}\right)$, worship place $\left(X_{8}\right)$, pavement $\left(X_{9}\right)$, communication tower $\left(X_{10}\right)$, cooperative $\left(X_{11}\right)$, and store/stall $\left(X_{12}\right)$. Twelve (12) research variables are reduced to the new variable in the form of principal component. The principal component analysis shows the sub-district potency data in Palu 2017 formed three principal components and can explain the variance of the data up to 89.98 percent overall.
\end{abstract}

Keywords : Principal Component Analysis, Earthquake and Tsunami, Potency of Palu

\begin{abstract}
Abstrak
Pada tanggal 28 September 2018 peristiwa gempa bumi berkekuatan 7,4 SR diikuti dengan tsunami melanda Kota Palu. Gempa bumi dan tsunami memakan ribuan korban jiwa, ribuan orang mengungsi, ribuan bangunan hancur dan kerusakan infrastruktur di Kota Palu. Selain itu, dampak bencana gempa bumi dan tsunami ini berpengaruh terhadap pembangunan Kota Palu. Pembangunan yang susah payah dibangun dan memerlukan waktu lama, tiba-tiba hancur seketika karena gempa bumi dan tsunami. Penelitian ini difokuskan pada potensi kecamatan di Kota Palu sebelum terjadi bencana gempa bumi dan tsunami. Adapun data yang digunakan berasal dari publikasi Kota Palu dalam angka 2018 yang diperoleh dari BPS Kota Palu. Variabel pada penelitian ini merupakan variabel yang diambil dari berbagai aspek yakni geografi, pemerintahan, sosial, transportasi, komunikasi, dan ekonomi. Adapun rincian variabel penelitiannya adalah luas kecamatan $\left(\mathrm{X}_{1}\right)$, kelurahan/desa $\left(\mathrm{X}_{2}\right)$, Penduduk $\left(\mathrm{X}_{3}\right), \mathrm{SD} /$ sederajat $\left(\mathrm{X}_{4}\right)$, SLTP/sederajat $\left(\mathrm{X}_{5}\right)$, SLTA/sederajat $\left(\mathrm{X}_{6}\right)$, fasilitas kesehatan $\left(\mathrm{X}_{7}\right)$, tempat ibadah $\left(\mathrm{X}_{8}\right)$, jalan aspal $\left(\mathrm{X}_{9}\right)$, menara telekomunikasi/tower $\left(\mathrm{X}_{10}\right)$, koperasi $\left(\mathrm{X}_{11}\right)$, dan took/kios $\left(\mathrm{X}_{12}\right)$. Dua belas variabel yang diteliti tersebut disederhanakan ke dalam variabel baru berupa komponen utama. Hasil analisis komponen utama menunjukkan data potensi kecamatan di Kota Palu tahun 2017 terbentuk tiga komponen utama serta dapat menjelaskan varian data secara keseluruhan sebesar 89,98 persen.
\end{abstract}

Kata kunci : Analisis Komponen Utama, Gempa Bumi dan Tsunami, Potensi Kota Palu

* Prodi Magister Statistika Terapan,Universitas Padjajaran

Email address: drajatindrapurnama@bps.go.id 


\section{PENDAHULUAN}

Indonesia merupakan salah satu negara dengan aktifitas kegempaan teraktif di dunia. Hal ini disebabkan karena Indonesia dikelilingi lempeng Indo-Australia dan Pelat Laut Filipina yang meretas di bawah lempeng Eurasia, dengan 5 (lima) pulau besar dan beberapa

semenanjung. Indonesia telah mengalami ribuan gempa bumi dan ratusan tsunami pada rentang empat ratus tahun terakhir [1]. Sumatera dan Jawa adalah dua pulau yang paling rentan dampak tsunami karena terletak langsung di depan Lempeng Indo-Australia. Papua dan Sulawesi juga pernah mengalami beberapa tsunami, walaupun tidak sesering Sumatera dan Jawa. Tetapi belakangan ini, Sulawesi dengan beberapa daerah rawan subduksinya telah menjadi lebih aktif yang mengakibatkan banyaknya aktivitas kegempaan, terutama dengan pusat gempa di laut.

Kota Palu, ibukota Provinsi Sulawesi Tengah tercatat sebagai daerah rawan gempa karena memiliki aktivitas tektonik tertinggi di Indonesia. Pasalnya, di Kota Palu terdapat patahan kerak Bumi (sesar) berdimensi cukup besar yang dikenal dengan nama sesar PaluKoro. Sesar Palu-Koro memanjang sekitar 500 kilometer mulai dari Selat Makassar sampai Pantai Utara Teluk Bone. Di Kota Palu, sesar melintas dari Teluk Palu masuk ke wilayah daratan, memotong jantung kota sampai ke Sungai Lariang di Lembah Pipikoro.

Pada tanggal 28 September 2018 peristiwa gempa bumi berkekuatan 7,4 SR diikuti dengan tsunami yang melanda pantai barat Pulau Sulawesi. Pusat gempa berada di $26 \mathrm{~km}$ utara Kabupaten Donggala dan $80 \mathrm{~km}$ barat laut Kota Palu dengan kedalaman $10 \mathrm{~km}$. Guncangan gempa bumi dirasakan di Kabupaten Donggala, Kota Palu, Kabupaten Parigi Moutong, Kabupaten Sigi, Kabupaten Poso, Kabupaten Tolitoli, Kabupaten Mamuju bahkan hingga Kota Samarinda, Kota Balikpapan, dan Kota Makassar. Gempa bumi memicu tsunami hingga ketinggian 5 meter di Kota Palu. Menurut BNPB [2], dampak bencana gempa bumi dan tsunami tercatat 2.256 orang meninggal dunia. Sebarannya di Kota Palu 1.703 orang, Donggala 171 orang, Sigi 366 orang, Parigi Moutong 15 orang dan Pasangkayu 1 orang. Dari segi infrastruktur, banyak bangunan yang hancur akibat gempa bumi dan tsunami. Kerusakan meliputi 68.451 unit rumah, 327 unit tempat ibadah, 265 unit sekolah, perkantoran 78 unit, toko 362 unit, jalan 168 titik retak, jembatan 7 unit dan sebagainya. Kerusakan dan kerugian dari bencana ini mencapai 13,82 trilyun rupiah.

Dampak bencana gempa bumi dan tsunami ini berpengaruh terhadap pembangunan Kota Palu. Pembangunan yang susah payah dibangun dan memerlukan waktu lama, tiba-tiba hancur seketika karena gempa bumi dan tsunami. Bahkan pertumbuhan pembangunan di wilayah terdampak bencana menjadi minus atau mengalami kemunduran dalam rentang waktu tertentu. Tujuan dari penelitian ini adalah melihat potensi kecamatan di Kota Palu sebelum terjadinya gempa bumi dan tsunami pada 28 September 2018. Potensi yang dilihat adalah potensi dari berbagai aspek kehidupan dan menyerderhadakan berbagai aspek tersebut ke dalam komponen utama. Hal ini agar nantinya bisa sebagai pembanding atau masukan untuk pembangunan kembali Kota Palu pasca bencana gempa dan tsunami.

\section{METODE PENELITIAN}




\section{Drajat Indra Purnama}

\subsection{Metode Pengumpulan Data}

Data yang digunakan merupakan data sekunder dari Badan Pusat Statistik Kota Palu tahun 2017 [3]. Objek penelitian adalah 8 Kecamatan di Kota Palu. Data potensi kecamatan di Kota Palu merupakan fokus penelitian ini. Variabel pada penelitian ini merupakan variabel yang diambil dari berbagai aspek yakni geografi (luas kecamatan), pemerintahan (jumlah kelurahan/desa), sosial (jumlah sekolah, tempat ibadah, dan fasilitas kesehatan), transportasi (panjang jalan aspal), komunikasi (jumlah tower), dan ekonomi (jumlah koperasi dan toko/kios). Adapun rincian variabel penelitian data potensi kecamatan di Kota Palu tahun 2017 yang sekaligus dinyatakan sebagai variabel independen disajikan pada Tabel 1.

Tabel 1: Variabel Penelitian

\begin{tabular}{ccl}
\hline No. & Variabel & \multicolumn{1}{c}{ Keterangan } \\
\hline$(1)$ & $(2)$ & \multicolumn{1}{c}{$(3)$} \\
\hline 1. & $\mathrm{X}_{1}$ & Luas Kecamatan $\left(\mathrm{Km}^{2}\right)$ \\
2. & $\mathrm{X}_{2}$ & Kelurahan/Desa \\
3. & $\mathrm{X}_{3}$ & Penduduk (Ribu Jiwa) \\
4. & $\mathrm{X}_{4}$ & SD/Sederajat \\
5. & $\mathrm{X}_{5}$ & SLTP/Sederajat \\
6. & $\mathrm{X}_{6}$ & SLTA/Sederajat \\
7. & $\mathrm{X}_{7}$ & Fasilitas Kesehatan \\
8. & $\mathrm{X}_{8}$ & Tempat Ibadah \\
9. & $\mathrm{X}_{9}$ & Jalan Aspal (Km) \\
10. & $\mathrm{X}_{10}$ & Menara Telekomunikasi/Tower \\
11. & $\mathrm{X}_{11}$ & Koperasi \\
12. & $\mathrm{X}_{12}$ & Toko/Kios \\
\hline
\end{tabular}

\subsection{Metode Analisis Data}

Metode analisis yang digunakan dalam penelitian ini adalah Analisis Komponen Utama. Adapun tahapan yang harus dilalui adalah sebagai berikut :

1. Uji Korelasi

Pengujian ini dilakukan untuk mengetahui hubungan antara variabel independen data potensi kecamatan di Kota Palu tahun 2017. Pengolahan data untuk menghasilkan nilai uji ini yaitu dengan menggunakan software R seri 3.5.1.

2. Analisis Komponen Utama

Analisis komponen utama digunakan untuk mengetahui jumlah komponen utama yang akan dibentuk dengan pendekatan nilai eigen, proporsi varian kumulatif, dan scree plot.

\subsection{Uji Korelasi Antar Variabel}

Uji kebebasan antar variabel menggunakan metode bartlett sphericity digunakan untuk mengetahui apakah terdapat korelasi atau hubungan antar variabel dalam kasus multivariat. Variabel $X_{1}, X_{2}, \ldots, X_{p}$ dikatakan bersifat saling bebas (independen) jika matriks korelasi antar variabel membentuk matriks identitas [5]. Pengujian kebebasan antar variabel ini dapat dilakukan uji bartlett sphericity dengan hipotesis sebagai berikut. 


\section{Drajat Indra Purnama}

$\mathrm{H}_{0}: \mathbf{R}=\mathrm{I}$ (Variabel independen tidak berkorelasi)

$\mathrm{H}_{1}: \mathbf{R} \neq \mathrm{I}$ (Variabel inependen berkorelasi)

Statiistik uji :

$$
\chi^{2}=\left\{n-1-\frac{2 p+5}{6}\right\} \ln |\boldsymbol{R}|
$$

dimana
$n$ : jumlah observasi
$p:$ jumlah variabel independen
$\mathbf{R}$ : matrik korelasi dari masing-masing variabel independen

Jika ditetapkan dengan menggunakan taraf signifikan $\alpha=0,05$ (5\%) diperoleh keputusan Tolak $\mathrm{H}_{0}$ jika nilai

$$
\chi_{\text {hitung }}^{2}=\chi_{\left(\alpha, \frac{1}{2} p(p-1)\right)}^{2}
$$

Sehingga dapat disimpulkan bahwa dalam kasus multivariat terdapat korelasi antar variabel independen.

\subsection{Analisis Komponen Utama}

Metode analisis komponen utama asalnya dikemukakan K Pearson sebagai alat fitting bidang dengan kuadrat terkecil ortogonal, kemudian dikembangkan oleh $T$ Hotelling untuk tujuan menganalisa struktur korelasi [4].

Tujuan analisis komponen utama adalah sebagai berikut :

1. Reduksi variabel dengan menjaga informasi data asal sebanyak mungkin.

2. Untuk mendapatkan variabel baru yang bersifat orthogonal.

3. Mentransformasikan variabel independen yang saling berkorelasi menjadi variabel baru yang saling bebas, sehingga tidak terjadi korelasi antar variabel independennya.

Cara penggunaan analisis komponen utama adalah sebagai berikut :

1. Bila $\Sigma$ matriks varian-kovarian dari variabel random $x^{\prime}$. Pasangan nilai eigen dan vektor eigen $\Sigma$ adalah $\left(\lambda_{1}, e_{1}\right),\left(\lambda_{2}, e_{2}\right), \ldots,\left(\lambda_{p}, e_{p}\right)$ dimana $\lambda_{1} \geq \lambda_{2} \geq \cdots \geq \lambda_{p} \geq 0$, maka komponen utama ke$i$ adalah $Y_{i}=\underline{e}_{i}^{\prime} \underline{x}=e_{i 1} x_{1}+e_{i 2} x_{2}+\cdots+e_{i p} x_{p}, i=1,2, \ldots, p$ dengan $\operatorname{Var}\left(Y_{i}\right)=\underline{e}_{i}^{\prime} \underline{e}_{i}=\lambda_{i}$ $\operatorname{dan} \operatorname{Cov}\left(Y_{i}, Y_{k}\right)=\underline{e}_{i}^{\prime} \Sigma \underline{e}_{k}=0$.

2. Proporsi total varian yang diterangkan komponen utama ke- $k$ adalah $\frac{\lambda_{k}}{\lambda_{1}+\lambda_{2}+\cdots \lambda_{p}} ; k=1,2, \ldots p$

3. Korelasi komponen utama ke- $i$ dengan variabel asal ke- $k$ adalah $\rho_{Y_{i} k}=\frac{e_{i k} \sqrt{\lambda_{i}}}{\sigma_{i i}} ; i, k=1,2, \ldots, p$

4. Analisis komponen utama dari variabel yang distandarisasi adalah sebagai berikut $Z_{1}=$ $\left(\frac{x_{1}-\mu_{1}}{\sqrt{\sigma_{11}}}\right) ; Z_{2}=\left(\frac{x_{2}-\mu_{2}}{\sqrt{\sigma_{22}}}\right) ; \ldots ; Z_{p}=\left(\frac{x_{p}-\mu_{p}}{\sqrt{\sigma_{p p}}}\right) ;$ atau dalam notasi matriks $Z=\left(v^{\frac{1}{2}}\right)^{-1}(\underline{x}-\mu)$ dengan $v^{\frac{1}{2}}$ matriks diagonal dengn elemen $\sqrt{\sigma_{i i}}$ maka kovariansnya $Z=\left(v^{\frac{1}{2}}\right)^{-1} \Sigma\left(v^{\frac{1}{2}}\right)^{-1}=\rho$. Komponen utama ke-i adalah $Y_{i}=\underline{e}_{i}^{\prime} z=\underline{e}_{i}^{\prime}\left(v^{\frac{1}{2}}\right)^{-1}(\underline{x}-\mu)$. Proporsi varian yang diterangkan komponen ke- $k$ adalah $\frac{\lambda_{k}}{q}$ dimana $\lambda_{k}$ adalah nilai eigen dari $\rho$ dan $q=\operatorname{tr}(\rho)$.

\subsection{Kriteria Pemilihan Komponen Utama}




\section{Drajat Indra Purnama}

Salah satu tujuan dari analisis komponen utama adalah mereduksi dimensi data asal yang semula terdapat $p$ variabel independen menjadi $k$ komponen utama $(k<p)$. Terdapat beberapa cara menentukan $k$ komponen utama, diantaranya :

a. Menggunakan nilai eigen $>1$

b. Menggunakan proporsi kumulatif varian terhadap total varian. Proporsi kumulatif varian variabel inependen asal yang dijelaskan oleh $k$ komponen utama minimal 80 persen, dan proporsi total variansi populasi bernilai cukup besar [4].

c. Menggunakan scree plot yaitu plot antara $i$ dengan $\lambda_{i}$, pemilihan nilai $k$ berdasarkan scree plot ditentukan dengan melihat letak terjadinya belokan dengan menghapus komponen utama yang menghasilkan beberapa nilai eigen kecil membentuk pola garis lurus [6]. Bila kurva masih curam maka masih bisa dilakukan penambahan komponen, sebaliknya bila kurva sudah melandai maka penentuan jumlah komponen sudah selesai meskipun penentuan landai atau curamnya scree plot bersifat subjektif oleh setiap orang.

\section{HASIL DAN PEMBAHASAN}

Data input yang digunakan adalah matriks korelasi yang dibentuk dari data potensi kecamatan di Kota Palu tahun 2017. Matriks korelasi digunakan karena varian variabel independen cenderung tidak seragam. Berikut adalah nilai varian dari variabel independen.

Tabel 2 : Nilai varian variabel

\begin{tabular}{cc}
\hline Variabel & Varian \\
\hline$(1)$ & $(2)$ \\
\hline $\mathrm{X}_{1}$ & $4.349270 \mathrm{e}+03$ \\
$\mathrm{X}_{2}$ & $1.071429 \mathrm{e}+00$ \\
$\mathrm{X}_{3}$ & $4.777667 \mathrm{e}+02$ \\
$\mathrm{X}_{4}$ & $3.469643 \mathrm{e}+01$ \\
$\mathrm{X}_{5}$ & $1.698214 \mathrm{e}+01$ \\
$\mathrm{X}_{6}$ & $3.028571 \mathrm{e}+01$ \\
$\mathrm{X}_{7}$ & $7.450000 \mathrm{e}+01$ \\
$\mathrm{X}_{8}$ & $1.091696 \mathrm{e}+03$ \\
$\mathrm{X}_{9}$ & $3.953946 \mathrm{e}+03$ \\
$\mathrm{X}_{10}$ & $4.657143 \mathrm{e}+01$ \\
$\mathrm{X}_{11}$ & $4.698393 \mathrm{e}+02$ \\
$\mathrm{X}_{12}$ & $1.356229 \mathrm{e}+06$ \\
\hline
\end{tabular}

\subsection{Pengujian Korelasi}

The purpose of correlation test is knowing the relationship between the independent variables in the multivariate case in potential data of subdistricts in Palu Municipality in 2017. Here are the results correlation test of independent variables simultaneously.

Hipotesis :

$\mathrm{H}_{0}: \mathbf{R}=\mathrm{I}$ (Variabel indpenden tidak berkorelasi)

$\mathrm{H}_{1}: \mathbf{R} \neq \mathrm{I}$ (Variabel independen berkorelasi)

N Nilai uji bartlett sphericity (chi-square hitung) : 414,359

Nilai chi-sqaure tabel (derajat bebas 66) : 48,30538

$>$ Kesimpulan :

Karena nilai chi-square hitung lebih besar dari nilai chi-square tabel dengan alpha 5 persen dan derajat bebas 66 maka keputusan yang diambil adalah tidak cukup bukti untuk mengatakan bahwa variabel independen tidak berkorelasi secara simultan. 


\section{Drajat Indra Purnama}

\subsection{Analisis Komponen Utama}

Untuk keperluan reduksi variabel indepeden maka akan ditentukan berapa banyak komponen utama yang terbentuk. Penentuan komponen utama yang terbentuk adalah dengan menggunakan nilai eigen dan proporsi kumulatif varian terhadap total varian. Berikut disajikan nilai eigen untuk masingmasing komponen utama.

Tabel 3 : Nilai Eigen dan Proporsi Varian Kumulatif menurut Komponen

\begin{tabular}{ccc}
\hline Komponen & Nilai Eigen & $\begin{array}{c}\text { Proporsi Varian } \\
\text { Kumulatif }\end{array}$ \\
\hline$(1)$ & $(2)$ & $(3)$ \\
\hline 1 & $7.301626 \mathrm{e}+00$ & 0.6084688 \\
2 & $2.160007 \mathrm{e}+00$ & 0.7884694 \\
3 & $1.335541 \mathrm{e}+00$ & 0.8997644 \\
4 & $8.107312 \mathrm{e}-01$ & 0.9673254 \\
5 & $2.512803 \mathrm{e}-01$ & 0.9882654 \\
6 & $1.142491 \mathrm{e}-01$ & 0.9977862 \\
7 & $2.656610 \mathrm{e}-02$ & 1.0000000 \\
8 & $1.810208 \mathrm{e}-16$ & 1.0000000 \\
9 & $1.176795 \mathrm{e}-16$ & 1.0000000 \\
10 & $5.424427 \mathrm{e}-18$ & 1.0000000 \\
11 & $1.074084 \mathrm{e}-17$ & 1.0000000 \\
12 & $3.367553 \mathrm{e}-16$ & 1.0000000 \\
\hline
\end{tabular}

Pada tabel 3 terlihat jelas bahwa nilai nilai eigen lebih dari 1 terdapat pada komponen 1 sampai 3 sehingga dapat disimpulkan bahwa terdapat 3 komponen yang terbentuk. Secara keseluruhan, ketiga komponen utama tersebut dapat menjelaskan keragaman data potensi kecamatan di Kota Palu tahun 2017 sebesar 89,98 persen. Untuk lebih memperjelas pembentukan ketiga komponen tersebut, berikut disajikan gambar scree plot.

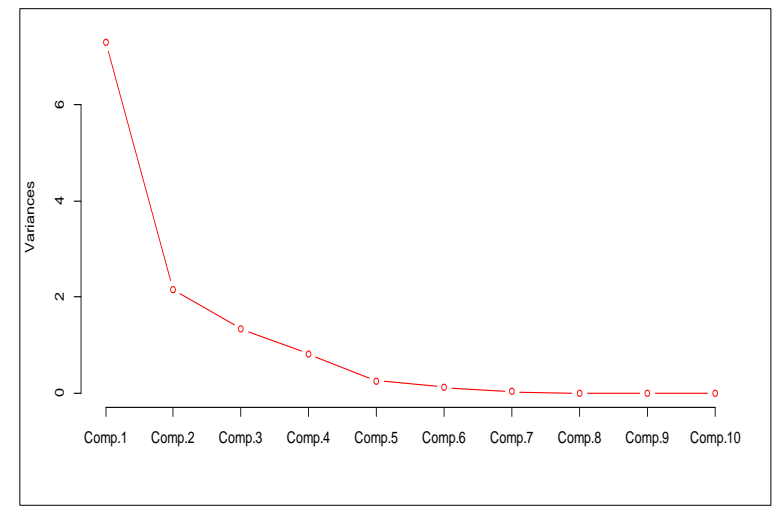

Gambar 1. Scree Plot

Pada gambar 1 di atas terlihat titik - titik yang menunjukkan nilai eigen dari masing-masing komponen. Komponen utama yang terbentuk dapat dilihat pada titik yang berada di atas 1 atau nilai eigen lebih dari 1 yaitu komponen 1, komponen 2, dan komponen 3. Jika menggunakan pendekatan 


\section{Drajat Indra Purnama}

titik elbow, tampak juga bahwa pada komponen ke-4 kurva sudah mulai landai (curam di sebelah kiri dan landai di sebelah kanan) sehingga dapat diambil tiga komponen sebelum komponen ke-4.

Selanjutnya, agar dapat memperoleh nilai komponen score dari komponen baru yang terbentuk untuk setiap observasinya, maka akan dihitung terlebih dahulu nilai koefisien transformasi dari variabel-variabel independen awal. Nilai koefisien transformasi ini akan membantu dalam penamaan komponen baru yang terbentuk, dilihat dari nilai koefisien transformasi yang terbesar di setiap komponennya. Berikut disajikan koefisien komponen utama menurut variabel.

Tabel 4. Koefisien Komponen Menurut Variabel

\begin{tabular}{|c|c|c|c|}
\hline Variabel & KU1 & KU2 & KU3 \\
\hline$(1)$ & $(2)$ & $(3)$ & $(4)$ \\
\hline$Z_{1}$ & 0,107 & $\mathbf{0 , 5 9 8}$ & 0,270 \\
\hline$Z_{2}$ & 0,119 & $\mathbf{0 , 5 7 4}$ & \\
\hline$Z_{3}$ & $\mathbf{0 , 3 5 5}$ & & $-0,169$ \\
\hline$Z_{4}$ & $\mathbf{0 , 3 1 1}$ & $-0,116$ & 0,125 \\
\hline$Z_{5}$ & $\mathbf{0 , 3 0 4}$ & $-0,226$ & $-0,118$ \\
\hline$Z_{6}$ & $\mathbf{0 , 3 5 9}$ & & 0,174 \\
\hline$Z_{7}$ & $\mathbf{0 , 3 2 3}$ & $-0,222$ & $-0,106$ \\
\hline$Z_{8}$ & $\mathbf{0 , 3 2 8}$ & 0,174 & $-0,320$ \\
\hline$Z_{9}$ & 0,229 & 0,318 & $\mathbf{- 0 , 4 5 1}$ \\
\hline$Z_{10}$ & $-0,186$ & & $\mathbf{- 0 , 7 0 3}$ \\
\hline$Z_{11}$ & $\mathbf{0 , 3 3 0}$ & $-0,234$ & 0,113 \\
\hline$Z_{12}$ & $\mathbf{0 , 3 5 0}$ & & \\
\hline
\end{tabular}

Tabel 4 menunjukkan bahwa ketiga komponen utama (KU1, KU2, dan KU3) merupakan kombinasi linear dari variabel independen asal. Ketiga komponen utama yang terbentuk adalah

Komponen Utama 1 (KU1)

Komponen 1 yang terbentuk lebih banyak dijelaskan oleh variabel $\mathrm{Z}_{3}, \mathrm{Z}_{4}, \mathrm{Z}_{5}, \mathrm{Z}_{6}, \mathrm{Z}_{7}, \mathrm{Z}_{8} \mathrm{Z}_{11}$ dan $\mathrm{Z}_{12}$ karena koefisien variabel tersebut adalah yang paling besar nilainya yaitu masing-masing 0,355 , 0,311, 0,304, 0,359, 0,323, 0,328, 0,330 dan 0,350. Dengan kata lain, penduduk, SD, SLTP, SLTA, fasiltas kesehatan, tempat ibadah, koperasi, dan kios berkorelasi kuat dengan komponen utama 1 yang terbentuk. Selanjutnya, komponen utama 1 dinamakan komponen utama sosial dan ekonomi. Model yang terbentuk untuk komponen utama 1 adalah

$$
\begin{aligned}
\mathrm{KU} 1= & 0,107 \mathrm{Z}_{1}+0,119 \mathrm{Z}_{2}+\mathbf{0 , 3 5 5} \mathrm{Z}_{3}+\mathbf{0 , 3 1 1} \mathrm{Z}_{4}+\mathbf{0 , 3 0 4} \mathrm{Z}_{5}+\mathbf{0 , 3 5 9} \mathrm{Z}_{6}+\mathbf{0 , 3 2 3} \mathrm{Z}_{7}+\mathbf{0 , 3 2 8} \mathrm{Z}_{8}+ \\
& 0,229 \mathrm{Z}_{9}-0,186 \mathrm{Z}_{10}+\mathbf{0 , 3 3 0} \mathrm{Z}_{11}-\mathbf{0 , 3 5 0} \mathrm{Z}_{12}
\end{aligned}
$$

Komponen Utama 2 (KU2)

Komponen 2 yang terbentuk lebih banyak dijelaskan oleh variabel $Z_{1}$ dan $Z_{2}$ karena koefisien kedua variabel yang paling besar nilainya yaitu masing-masing 0,598 dan 0,574. Dengan kata lain luas wilayah dan jumlah kelurahan/desa berkorelasi kuat dengan komponen utama 2 yang terbentuk. Selanjutnya, komponen utama 2 dinamakan komponen geografi dan pemerintahan. Model yang terbentuk untuk komponen utama 2 adalah

$\mathrm{KU} 2=\mathbf{0 , 5 9 8} \mathrm{Z}_{1}+\mathbf{0 , 5 7 4} \mathrm{Z}_{2}-0,116 \mathrm{Z}_{4}-0,226 \mathrm{Z}_{5}-0,222 \mathrm{Z}_{7}+0,1744 \mathrm{Z}_{8}+0,318 \mathrm{Z}_{9}-0,234 \mathrm{Z}_{11}$

Komponen Utama 3 (KU3) 


\section{Drajat Indra Purnama}

Komponen 3 yang terbentuk lebih banyak dijelaskan oleh variabel $Z_{9 \text { dan }} Z_{10}$ karena nilai koefisien variabelnya yang paling besar yaitu masing-masing 0,451 dan -0,703. Dengan kata lain jalan aspal dan menara telekomunikasi/tower berkorelasi kuat dengan komponen utama 3 yang terbentuk. Selanjutnya, komponen utama 3 dinamakan komponen transportasi dan komunikasi. Model yang terbentuk untuk komponen utama 3 adalah

$$
\begin{aligned}
\mathrm{KU} 3= & 0,270 \mathrm{Z}_{1}-0,169 \mathrm{Z}_{3}+0,125 \mathrm{Z}_{4}-0,118 \mathrm{Z}_{5}+0,174 \mathrm{Z}_{6}-0,106 \mathrm{Z}_{7}-0,320 \mathrm{Z}_{8}-\mathbf{0 , 4 5 1} \mathrm{Z}_{9}- \\
& \mathbf{0 , 7 0 3} \mathrm{Z}_{10}+0,113 \mathrm{Z}_{11}
\end{aligned}
$$

\section{KESIMPULAN DAN SARAN}

\subsection{Kesimpulan}

Berdasarkan hasil analisis terhadap data potensi kecamatan di Kota Palu tahun 2017 dapat disimpulkan sebagai berikut :

1. Pengujian korelasi menunjukkan bahwa adanya korelasi antar variabel independen secara simultan.

2. Hasil analisis komponen utama terhadap 12 variabel penelitian pada data potensi kecamatan di Kota Palu tahun 2017 menunjukkan bahwa terdapat tiga komponen utama yang terbentuk yaitu komponen sosial dan ekonomi, komponen geografi dan pemerintahan, dan komponen transportasi dan komunikasi.

3. Ketiga komponen utama yang terbentuk tersebut dapat menjelaskan varian data secara keseluruhan sebesar 89,98 persen.

4. Metode analisis komponen utama dapat digunakan untuk data potensi kecamatan di Kota Palu tahun 2017. Hal ini dapat dilihat dari paling tidak terdapatnya 1 variabel yang berkorelasi kuat dengan komponennya (nilai korelasi di atas 0.5 ).

\subsection{Saran}

Analisis komponen utama pada penelitian ini menggunakan data potensi kecamatan di Kota Palu sebelum gempa bumi dan tsunami. Pembaca dapat menggunakan analisis komponen utama pada data potensi kecamatan di Kota Palu setelah gempa bumi dan tsunami sebagai pembanding keadaan di Kota Palu sebelum dan sesudah gempa bumi dan tsunami.

\section{DAFTAR PUSTAKA}

[1] Aydan, O. 2008. Seismic and Tsunami Hazard Potential in Indonesia with a special emphasis on Sumatra Island. Journal of The School of Marine Science and Technology, Tokai University.

[2] Badan Nasional Penanggulangan Bencana. Diakses Pada Tanggal 17. Desember 2018 Melalui https://bnpb.go.id/kerugian-dan-kerusakan-dampak-bencana-di-sulawesi-tengah-mencapai-1382trilyun-rupiah

[3] BPS Kota Palu. 2018. Kota Palu Dalam Angka 2018. Palu : BPS Kota Palu.

[4] Johnson, R.A. dan Wichern, D.W. 2002. Applied Multivariate Statistical Analysis, 5th edition. Pearson Education International.

[5] Morrison, Donald F. 1978. Multivariate Statistical Methods, Second edition. New York : McGraw-Hill.

[6] Rencher, A.C. 1998. Multivariate Statistical Inference and Application. Wiley-Interscience Publication, Brigham. 